\title{
Decreased methylation in the SNAI2 and ADAM23 genes associated with de- differentiation and haematogenous dissemination in breast cancers
}

Lenka Kalinkova', Iveta Zmetakova', Bozena Smolkova', Gabriel Minarik², Tatiana Sedlackova², Viera Horvathova Kajabova', Zuzana Cierna ${ }^{3}$, Michal Mego ${ }^{4}$ and Ivana Fridrichova ${ }^{*^{*}}$ (D)

\begin{abstract}
Background: In breast cancer (BC), deregulation of DNA methylation leads to aberrant expressions and functions of key regulatory genes. In our study, we investigated the relationship between the methylation profiles of genes associated with cancer invasivity and clinico-pathological parameters. In detail, we studied differences in the methylation levels between BC patients with haematogenous and lymphogenous cancer dissemination.

Methods: We analysed samples of primary tumours (PTs), lymph node metastases (LNMs) and peripheral blood cells (PBCs) from 59 patients with sporadic disseminated BC. Evaluation of the DNA methylation levels of six genes related to invasivity, ADAM23, UPA, CXCL12, TWIST1, SNAI1 and SNA12, was performed by pyrosequencing.

Results: Among the cancer-specific methylated genes, we found lower methylation levels of the SNAI2 gene in histologic grade 3 tumours $(\mathrm{OR}=0.61 ; 95 \% \mathrm{Cl}, 0.39-0.97 ; P=0.038)$ than in fully or moderately differentiated cancers. We also evaluated the methylation profiles in patients with different cancer cell dissemination statuses (positivity for circulating tumour cells (CTCS) and/or LNMs). We detected the significant association between reduced DNA methylation of ADAM23 in PTs and presence of CTCs in the peripheral blood of patients $(\mathrm{OR}=0.45 ; 95 \% \mathrm{Cl}$, $0.23-0.90 ; P=0.023)$.

Conclusion: The relationships between the decreased methylation levels of the SNAI2 and ADAM23 genes and cancer de-differentiation and haematogenous dissemination, respectively, indicate novel functions of those genes in the invasive processes. After experimental validation of the association between the lower values of SNAI2 and ADAM23 methylation and clinical features of aggressive BCs, these methylation profiles could improve the management of metastatic disease.
\end{abstract}

Keywords: SNA12 methylation, ADAM23 methylation, Breast cancer, Cancer cell de-differentiation, Haematogenous dissemination

\footnotetext{
* Correspondence: ivana.fridrichova@savba.sk

${ }^{1}$ Department of Genetics, Cancer Research Institute, Biomedical Research

Center, Slovak Academy of Sciences, v.v.i., Dubravska cesta 9, 84505

Bratislava, Slovak Republic

Full list of author information is available at the end of the article
}

(c) The Author(s). 2018 Open Access This article is distributed under the terms of the Creative Commons Attribution 4.0 International License (http://creativecommons.org/licenses/by/4.0/), which permits unrestricted use, distribution, and reproduction in any medium, provided you give appropriate credit to the original author(s) and the source, provide a link to the Creative Commons license, and indicate if changes were made. The Creative Commons Public Domain Dedication waiver (http://creativecommons.org/publicdomain/zero/1.0/) applies to the data made available in this article, unless otherwise stated. 


\section{Background}

Breast cancer (BC) is one of the most common tumours occurring in women worldwide, with high mortality rates [1]. In recent population study, it was observed that of $13,785 \mathrm{BC}$ patients undergoing adjuvant chemotherapy, $24.4 \%$ developed metastatic disease, with median survival of 20 months. In contrast to previous studies, no general improvement of survival in metastatic recurrent $\mathrm{BC}$ patients after chemotherapy has been evidenced over the last three decades [2]. Therefore, to assist in the development of effective diagnostic and therapeutic strategies for $\mathrm{BC}$, the identification of more precise biomarkers is necessary.

It is generally accepted that during the initiation and progression of cancer, deregulation of epigenetic processes, including DNA methylation, occurs and results in aberrant expression and function of a number of key regulatory genes $[3,4]$. Changes in DNA methylation in primary tumours (PTs) compared with normal breast tissues have been partially identified by numerous researchers; however, whole-genome bisulfite sequencing technology is now available, which allows the comprehensive analysis of normal and BC methylomes [5].

The metastatic cascade involves multiple steps enabling the detachment of cancer cells from PTs, their intravasation to the circulatory system, their avoidance of the immune reaction and their migration through the circulation. Some tumour cells can extravasate from vessels and invade distant organs. In a new microenvironment, tumour cells can persist in a dormant stage or form micrometastases, which can later develop into macrometastases [6-9].

The critical processes underlying the spread of cancer cells include the degradation of the basement membrane (BM) and the extracellular matrix (ECM). The BM is formed by dense interconnected sheets of ECM proteins, and the loss of tissue architecture and the disruption of structural boundaries between the epithelium and the stroma are the typical features of advanced stages of malignancy [10]. ADAMs (a disintegrin and metalloproteases) have been defined as transmembrane proteins with protease and adhesion functions [11]. ADAM23 belongs to the ADAM protein family although it does not have metalloprotease activity; however, its disintegrin-like domain facilitates its interaction with integrins, resulting in integrin-dependent cell adhesion [12-14]. Cancer cells not expressing $A D A M 23$ have higher migration capacities in cell line models [15]. Moreover, promoter hypermethylation of the $A D A M 23$ gene in breast PTs is significantly associated with more advanced grade, higher proliferation of cancer cells, poor prognosis and lower survival rates [15-17].

Cancer cells contribute to the degradation of the ECM by secreting various proteolytic enzymes, such as urokinase plasminogen activator (uPA). uPA is a serine protease that contributes to the conversion of inactive plasminogen to plasmin and that, in cooperation with the uPA receptor (uPAR), degrades the fundamental ECM components, such as laminin and fibronectin [18]. Several in vitro and in vivo studies have documented the essential role of uPA in tumour growth, the detachment of cancer cells from PT and haematogenous dissemination $[19,20]$. Moreover, the prognostic impact of uPA and plasminogen activator inhibitor-1 (PAI-1) expression levels has been identified predominantly in patients with HER2+ tumours [21]. Experimental studies have documented that promoter methylation is the dominant mechanism of $u P A$ silencing in $\mathrm{BC}$ progression $[22,23]$. Previously, the complete demethylation of the $u P A$ gene and expression of $u P A$ mRNA was found only in highly invasive oestrogen receptor-negative $\mathrm{BC}$ cell lines; in normal and low invasivity lines, $u P A$ hypermethylation with reduced mRNA expression was observed [24]. In BC patients, $U P A$ hypomethylation has been associated with metastatic disease, but the $u P A$ hypermethylation in non-selected $\mathrm{BC}$ was evidenced using the more complex methylation analyses of multiple CpG islands [24, 25].

Invasion by cancer cells occurs at the interface between tumour and host tissue, and the intensive exchange of many enzymes, chemokines and cytokines contributes to the destruction of the BM, the local modulation of the ECM and the stimulation of cancer cell migration [26]. Chemokine CXC motif ligand 12 (CXCL12), which is produced at high levels by cells of the tumour microenvironment and target tissues including lymph nodes, interacts with its signal receptor, CXCR4, expressed on the surface of cancer cells. Using the chemotactic gradient of CXCL12-CXCR4, CXCL12 participates in the regulation of the metastatic process $[27,28]$. Both encoding genes, CXCL12 and CXCR4, are epigenetically regulated during the modulation of metastatic potential in $\mathrm{BC}$. In patients with histologically advanced disease and worse survival, CXCL12 methylation and CXCR4 overexpression without methylation have been found [29-31]. In our previous study we documented the relationship between CXCL12 hypermethylation and increased risk for the development of LNMs in BC patients [17].

For the infiltration of epithelial cancer cells into circulation, it is necessary for them to shift into a more mesenchymal phenotype through the epithelial-mesenchymal transition (EMT). In normal physiological development, EMT is active in embryonal and organ development. In epithelial tumours, EMT contributes to the loss of cancer cell polarity, cell-cell contacts and cell-BM interactions. Owing to these mesenchymal characteristics, cancer cells obtain the capacity to migrate and invade, and they became be more resistant to apoptosis [32]. The EMT 
process is regulated by three main families of transcription factors (TFs), Zeb, Snail and Twist. Of these TFs, ZEB1 and ZEB2 (zinc finger E-box binding homeobox $1 / 2$ ), SNAI1 and SNAI2 (snail family zinc finger 1/2) and TWIST1 and TWIST2 (basic helixloop-helix transcription factor $1 / 2$ ) are known as direct regulators of the adhesion molecule E-cadherin [33]. Using immunohistochemical analyses, changes in Twist, Snail and Slug expressions have been observed in BC. In patients with metastatic disease, increasing levels of TWIST protein are associated with cancercaused death, and higher levels of SLUG (SNAI2) protein are present in cases with higher tumour grades [34]. More prevalent TWIST1 hypermethylation has been observed in $\mathrm{BC}$ compared to normal breast tissue; however, no direct evidence of the epigenetic regulation of TWIST1 mRNA or the relevant protein expression has been found [35-37]. Higher TWIST1 methylation levels have been evidenced in non-triple negative (TN) BC than in $\mathrm{TN} B C$ and in ductal compared to lobular invasive carcinomas [38, 39]. The dynamic changes in DNA methylation in genes encoding other two EMT-TFs, SNAI1 and SNAI2, have been observed in a EMT/MET cell-line model, where increased methylation was associated with decreased transcription in both genes [40]. In a previous in vitro study, regardless of the significantly higher expression levels of both SNAI2 and ZEB2 genes in metastatic $\mathrm{BC}$ cell lines, only moderate DNA methylation differences were found in SNAI2 between highly and poorly metastatic lines, which was in contrast to the ZEB2 gene, which was markedly hypomethylated in highly metastatic cell lines [41]. These results indicate more complex interactions in the epigenetic regulation of cancer invasivity including EMT.

Cancer cells disseminate from PTs either via blood vessels after intensive neo-vascularisation (haematogenous spread) or via the lymphatic system, named lymphogenous spread, which occurs after neo-lymphangiogenesis $[42,43]$. In cancers, the active growth of new blood vessels from pre-existing ones is triggered by tumour cells expressing vascular endothelial growth factor A (VEGFA) in the hypoxic microenvironment of tumour tissue. New angiogenic blood vessels are abnormal, with a lack of pericytes and BM connection and with some fenestrations, allowing intravasation and the haematogenous spread of cancer cells [44]. In BC, it has been found that endothelial cells produce soluble factors, such as hepatocyte growth factor (HGF), which contribute to EMT [45]. Several studies have shown that in numerous cancer types including $\mathrm{BC}$, the neo-vascularization associated with the presence of circulating tumour cells (CTCs) in blood vessels and the higher number of CTCs are correlated with poor prognosis and decreased overall survival [46-49]. On the other hand, tumour cells can express and secrete several lymphangiogenic factors, including VEGFC/D, to promote the formation of new lymphatic vessels in the tumour stroma [50]. From the lymphatic vasculature, cancer cells can enter the blood circulation via the thoracic duct or form metastases in lymph nodes. Moreover, cancer cell motility and spread are affected by the density of blood and lymphatic vessels, the interstitial blood pressure, tumour hypoxia, regional lymph node metastases (LMNs) and the recently discovered primo vascular system [42]. The preferred dissemination route of cancer cells depends on cancer types and microenvironmental conditions, but it has already been reported that carcinomas, such as BC, and melanomas more often spread through the lymphatic vessels and develop LNMs, in comparison to soft tissue sarcomas, which predominantly result in systematic metastasis [51, 52].

In our previous study of methylation profiles in 206 BC patients we showed that the risk for LNMs development and higher proliferation of cancer cells was increased by hypermethylation of CXCL12 and ADAM23 genes, respectively [17]. For present study, we selected $59 \mathrm{BC}$ patients with haematogenous and/or lymphogenous cancer dissemination to investigate more deeply the relationship between the DNA methylation patterns and the clinico-pathological parameters of more aggressive BC. In addition to CXCL12, ADAM23 and $u P A$ genes contributing to the inhibition of cell adhesion, BM degradation and ECM remodelling, TWIST1, SNAI1 and SNAI2 genes, the protein products of which are known as key inducers of EMT, were involved. The changes in methylation levels of patients with haematogenous and/or lymphogenous dissemination of BC could help to identify potential biomarkers for metastatic potential of $\mathrm{BC}$ alone and also for different routes of metastatic progression.

\section{Methods \\ Patients and samples}

In the present study we analysed PT tissues and LNM samples, both isolated from formalin fixed paraffin-embedded tissues (FFPE) and peripheral blood cells (PBCs) from 59 selected patients with disseminated BC. Their tumours were considered as sporadic, because these patients did not fulfil criteria for hereditary BC testing. PBC samples from 53 healthy women and 10 normal mammary gland samples from mammoplasties were used as controls. PT and LNM specimens were collected at the National Cancer Institute in Bratislava, Slovakia between 2012 and 2014, and the control samples were collected in previous studies. This study was approved by the Institutional Review Board of the National Cancer Institute of Slovakia, and written informed consent was obtained from all patients and controls. The clinical and histopathological characteristics were obtained from 
patient records, and the tumours were defined according to TNM classification. The clinico-histopathological data of evaluated patients are summarized in Table 1 [53]. No patient underwent preoperative radiotherapy or chemotherapy before sample collection. The age of the women with $\mathrm{BC}$ ranged from 37 to 79 years (mean 60.19 \pm

Table 1 Clinical characteristics

\begin{tabular}{|c|c|c|c|}
\hline Variables & & $n$ & $\%$ \\
\hline All & & 59 & 100.0 \\
\hline \multirow[t]{2}{*}{ Age } & $\leq 50$ & 13 & 22.0 \\
\hline & $>50$ & 46 & 78.0 \\
\hline \multirow[t]{2}{*}{ Histology } & DIC & 49 & 83.1 \\
\hline & Others & 10 & 16.9 \\
\hline \multirow[t]{2}{*}{ Tumour size (mm) } & $\leq 20$ & 34 & 57.6 \\
\hline & $>20$ & 25 & 42.4 \\
\hline \multirow[t]{2}{*}{ LNM status $^{a}$} & 0 & 17 & 28.8 \\
\hline & $\geq 1$ & 42 & 71.2 \\
\hline \multirow[t]{3}{*}{ TNM classification } & । & 14 & 23.7 \\
\hline & $\|$ & 22 & 37.3 \\
\hline & III & 23 & 39.0 \\
\hline \multirow[t]{2}{*}{ Grade } & 1 and 2 & 36 & 63.2 \\
\hline & 3 & 21 & 36.8 \\
\hline \multirow[t]{2}{*}{ Hormone receptor status ${ }^{b}$} & Negative & 8 & 13.6 \\
\hline & Positive & 51 & 86.4 \\
\hline \multirow[t]{2}{*}{ HER2 status $^{c}$} & Normal & 16 & 27.1 \\
\hline & Amplified & 43 & 72.9 \\
\hline \multirow[t]{2}{*}{ Ki-67 proliferative index ${ }^{d}$} & Low & 35 & 59.3 \\
\hline & High & 24 & 40.7 \\
\hline \multirow[t]{2}{*}{ Tumour multifocality } & Negative & 51 & 87.9 \\
\hline & Positive & 7 & 12.1 \\
\hline \multirow[t]{2}{*}{ CTC any ${ }^{e}$} & Negative & 30 & 50.8 \\
\hline & Positive & 29 & 49.2 \\
\hline \multirow[t]{2}{*}{ CTC epithelial } & Negative & 45 & 76.3 \\
\hline & Positive $^{f}$ & 14 & 23.7 \\
\hline \multirow[t]{2}{*}{ CTC mesenchymal } & Negative & 40 & 67.8 \\
\hline & Positive ${ }^{g}$ & 19 & 32.2 \\
\hline \multirow[t]{3}{*}{$\mathrm{CTC}^{\mathrm{e}}$ and LNM status } & Negat. / Posit. & 29 & 50.0 \\
\hline & Posit. / Negat. & 16 & 27.6 \\
\hline & Posit. / Posit. & 13 & 22.4 \\
\hline
\end{tabular}

Abbreviations: DIC ductal invasive carcinoma, LNM lymph node metastasis, HER2 human epidermal growth factor receptor 2, CTC circulating tumour cell a LNM status was categorized according to the number of metastatic LNs

${ }^{b}$ Negative for both (oestrogen receptor and progesterone receptor) or positive for either with cut-off $10 \%$

'HER2 status was determined immunohistochemically according to ASCO guidelines [53]

${ }^{\mathrm{d} C u t-o f f} 20 \%$

${ }^{e} \mathrm{CTCS}$ were detected through the quantification of EMT-inducing transcription factor gene transcripts

fOut of them $4 \mathrm{BC}$ patients had simultaneously mesenchymal CTC

${ }^{9}$ Out of them 4 BC patients had simultaneously epithelial CTC
10.38 years). The $\mathrm{PBC}$ samples were obtained from control women aged 40 to 85 years (mean $58.17 \pm$ 10.50 years). The age of the normal breast tissue donors ranged from 31 to 56 years (mean $46.90 \pm 9.06$ years). No control persons had signs or symptoms of cancer or other serious diseases.

\section{DNA extraction and sodium bisulfite DNA modification}

The representative samples of PTs (minimally $80 \%$ of cancer cells), LNMs and healthy tissues from mammary glands were selected from FFPE blocks. Tissue samples identified under light microscope were marked and $3 \mathrm{~mm}$ diameter cores of tissue were removed from donor blocks into the recipient master block using a tissue microarray method, as described previously [54]. DNA was extracted by the MagneSil Genomic Fixed Tissue System (Promega, Madison, Wisconsin, USA). DNA from PBCs was isolated using the FlexiGene DNA Kit (Qiagen, Hilden, Germany). All extraction methods were performed according to the manufacturer's instructions. A NanoDrop 1000 spectrophotometer (Thermo Fisher Scientific, Bremen, Germany), was used to measure DNA concentration. DNA bisulfite modification was performed by the EpiTect Bisulfite Kit (Qiagen, Hilden, Germany) and the CpGenome DNA Modification Kit (Chemicon, Temecula, California, USA) for FFPEs $(2 \mu \mathrm{g}$ of isolated DNA) and PBC samples $(1 \mu \mathrm{g}$ of isolated DNA), respectively. The samples of modified DNA were divided into aliquots and stored at $-18{ }^{\circ} \mathrm{C}$. The principle of DNA bisulfite modification is the conversion of unmethylated cytosines to uracils, while methylated cytosines remain unchanged.

\section{PCR and methylation analyses}

For the evaluation of the DNA methylation profiles in the six selected cancer-associated genes (ADAM23, $u P A$, CXCL12, TWIST1, SNAI1 and SNAI2), the quantitative pyrosequencing method was used. Between 3 and 8 CpGs were analysed in each gene in the CpG islands of the promoter regions flanking the transcription start site. The primers for PCR and the pyrosequencing reactions were designed by PyroMark Assay Design software 2.0 (Qiagen, Hilden, Germany). The primers are shown in Table 2. All the designed assays were validated according to the manufacturer's instructions. The PCR reactions were performed by the PyroMark PCR Kit (Qiagen, Hilden, Germany) following manufacturer's instructions. The concentrations of the PCR primers were $0.32 \mu \mathrm{M}$ for UPA, CXCL12, TWIST1, SNAI1, and SNAI2 and $0.40 \mu \mathrm{M}$ for $A D A M 23$, with the annealing conditions of $56{ }^{\circ} \mathrm{C}$ for $30 \mathrm{~s}$ except for the ADAM23 gene, for which $52{ }^{\circ} \mathrm{C}$ for $30 \mathrm{~s}$ was used. For pyrosequencing, the PyroGold Reagent Kit (Qiagen, Hilden, Germany) and PyroMark Q24 System were used, and the results were 
Table 2 Primers for PCR and pyrosequencing

\begin{tabular}{|c|c|c|c|c|c|}
\hline Gene & Orienta-tion & Sequence $\left(5^{\prime}-3^{\prime}\right)$ of PCR primer & PCR product (bp) & Sequence $\left(5^{\prime}-3^{\prime}\right)$ of pyrosequencing primer & Numb. of CpGs \\
\hline$A D A M 23^{a}$ & $\begin{array}{l}\text { Forward } \\
\text { Reverse }\end{array}$ & $\begin{array}{l}\text { [Biotin]GCGTCGTTTAGTATITITAGGTT } \\
\text { TCCCCAACCACTACTCCCT }\end{array}$ & 89 & ACTACTCCСТССССС & 8 \\
\hline UPA & $\begin{array}{l}\text { Forward } \\
\text { Reverse }\end{array}$ & $\begin{array}{l}\text { TAGGTGTATGGGAGGAAGTA } \\
\text { [Biotin]CTCCCTCCCCTATCTTACA }\end{array}$ & 165 & GTITIITAAATITTGTGAG & 7 \\
\hline $\mathrm{CXCL} 12^{\mathrm{b}}$ & $\begin{array}{l}\text { Forward } \\
\text { Reverse }\end{array}$ & $\begin{array}{l}\text { TAGTGGGGTTITGTTATAGGGATA } \\
\text { [Biotin]ACCTTAAACCTTCTCAAACTC }\end{array}$ & 121 & GGGTITTGTTATAGGGATAAT & 7 \\
\hline TWIST1 & $\begin{array}{l}\text { Forward } \\
\text { Reverse }\end{array}$ & $\begin{array}{l}\text { GAAGGGGAGGGAAGGGG } \\
\text { [Biotin]TAACAATTCCTCCTCCCA }\end{array}$ & 97 & GGGAGGGAAGGGGGAG & 3 \\
\hline SNAl1 & $\begin{array}{l}\text { Forward } \\
\text { Reverse }\end{array}$ & $\begin{array}{l}\text { GTATTTGTTAGGGGAGTGGT } \\
\text { [Biotin]ACCACCCCCCTITATCAC }\end{array}$ & 72 & GTTAGGGGAGTGGTIT & 6 \\
\hline SNAI2 & $\begin{array}{l}\text { Forward } \\
\text { Reverse }\end{array}$ & $\begin{array}{l}\text { [Biotin]GTTGGTTGGGTGTGGTGTAG } \\
\text { CCCTACCCCCCTAACTTCCAAATATAAT }\end{array}$ & 100 & CСTAACTTCCAAATATAATACAAC & 5 \\
\hline
\end{tabular}

${ }^{\mathrm{a}, \mathrm{b}}$ Set of PCR primers and pyrosequencing primers were previously published by Zmetakova and colleagues [54]

evaluated by PyroMark Q24 2.0.6 software (Qiagen, Hilden, Germany). Methylation levels were defined as the percentage of average methylation in all CpG sites in each individual gene.

\section{CTCs detection in peripheral blood}

CTCs were detected in $5 \mathrm{~mL}$ of peripheral blood depleted of CD45-positive (CD45+) cells for CTC enrichment using a quantitative real-time polymerase chain reaction (qRT-PCR) assay, as described previously $[55,56]$. Patient samples with higher levels of KRT19 gene transcripts than those of healthy donors were scored as epithelial CTC-positive, while patient samples with higher mRNA levels of EMT-transcription factors (TWIST1, SNAI1, SLUG (SNAI2) and ZEB1) than those of healthy donors were scored as mesenchymal CTC-positive. The expression of at least one of the markers (either epithelial or mesenchymal) at levels above the defined cut off was sufficient to define a sample as CTC-positive.

The highest expression levels of the KRT19 and EMT-inducing TF gene transcripts relative to that of GAPDH were $3.4 \times 10^{-3}$ (median $2.8 \times 10^{-6}$, range: 0 $3.4 \times 10^{-3}$ ) for KRT19, $7.5 \times 10^{-4}$ (median 0, range: 0 $\left.7.5 \times 10^{-4}\right)$ for TWIST1, $3.8 \times 10^{-2}$ (median $3.1 \times 10^{-3}$, range: $5.0 \times 10^{-4}-3.8 \times 10^{-2}$ ) for SNAIL1 and $1.7 \times 10^{-1}$ (median $1.4 \times 10^{-2}$, range: $2.2 \times 10^{-3}-1.7 \times 10^{-1}$ ) for $Z E B 1$, while SLUG transcripts were not detected in any of the samples from healthy donor. These highest expression values in healthy donors were used as "cutoff" to determine CTCs positivity [57].

\section{Statistical analyses}

SPSS statistics 15.0 software was used for the statistical analyses of the data. The normality of distribution was tested by the Shapiro-Wilk test. Normally distributed samples were tested by Student's t-test or analysis of variance (ANOVA) with Bonferroni's corrections. Nonparametric Mann-Whitney U or Kruskal-Wallis $\mathrm{H}$ tests were used for non-normally distributed data. According to the normality of data, Pearson's or Spearman's correlations were used. Univariate analyses were performed for categorical variables using $\mathrm{X} 2$ or Fisher's exact test. A statistical two-tailed significance was regarded as $P$ value $<0.05$. A logistic regression adjusted for age was used to determine the effect of independent categorical variables and DNA methylation on the clinical status and tumour dissemination.

\section{Results \\ DNA methylation in various sample types in BC patients and controls}

In this study, we evaluated specific DNA methylation levels by the quantitative pyrosequencing method in three types of samples isolated from 59 BC patients, namely, in PT and LNM tissues and PBCs. From the six analysed genes, higher DNA methylation levels were found in PTs for ADAM23, uPA, CXCL12 and TWIST1 genes, with values of $9.98 \%, 14.08 \%, 13.41 \%$ and $21.88 \%$, respectively. Similar methylation levels of these four genes were found in LMN samples, and a positive correlation between PT and LNM tissues was observed $(r=$ $0.598, P=<0.001 ; \quad r=0.498, P=0.011 ; \quad r=0.380, P=$ $0.013 ; r=0.428, P=0.026$; respectively). In $\mathrm{BC}$ patients, increased methylation levels were detected in PT and LNM samples compared with PBCs for all studied genes. Methylation results in different types of samples are summarized in Table 3.

Furthermore, in univariate analysis, we found significantly different methylation levels in $\mathrm{PBC}$ samples between $\mathrm{BC}$ patients and controls for ADAM23, $u P A$, $S N A I 1$ and $S N A I 2$, with $P$ values $\leq 0.001$ for all. Similarly, significant differences in DNA methylation between PT and normal breast tissues were observed for CXCL12, TWIST1 and SNAI2 genes $(P=0.001, P=0.006$ and $P=0.009$, respectively). However, these results cannot 
Table 3 The mean DNA methylation levels in healthy women and breast cancer patients in different types of samples

\begin{tabular}{|c|c|c|c|c|c|}
\hline \multirow[b]{2}{*}{ Genes } & \multicolumn{2}{|c|}{$\begin{array}{l}\text { DNA methylation levels - controls } \\
\text { Mean } \pm \text { std. deviation (in \%) }\end{array}$} & \multicolumn{3}{|c|}{$\begin{array}{l}\text { DNA methylation levels - breast cancer patients } \\
\text { Mean } \pm \text { std. deviation (in \%) }\end{array}$} \\
\hline & Peripheral blood cells & Mammary glands ${ }^{a}$ & Peripheral blood cells & Primary tumour & Lymph node metastasis \\
\hline ADAM23 & $2.13 \pm 0.39$ & $4.89 \pm 2.32$ & $2.50 \pm 0.64$ & $9.98 \pm 10.32$ & $9.94 \pm 10.89$ \\
\hline UPA & $1.29 \pm 0.64$ & $5.00 \pm 3.80$ & $2.20 \pm 0.83$ & $14.08 \pm 16.88$ & $9.45 \pm 12.49$ \\
\hline CXCL12 & $2.36 \pm 0.52$ & $4.00 \pm 1.94$ & $2.78 \pm 1.14$ & $13.41 \pm 13.32$ & $11.35 \pm 9.81$ \\
\hline TWIST1 & $4.44 \pm 1.15$ & $8.20 \pm 6.29$ & $4.15 \pm 1.42$ & $21.88 \pm 16.68$ & $15.23 \pm 12.90$ \\
\hline SNAl1 & $1.46 \pm 0.58$ & $3.80 \pm 2.04$ & $2.17 \pm 1.01$ & $6.04 \pm 6.71$ & $4.60 \pm 2.04$ \\
\hline SNAI2 & $2.37 \pm 0.63$ & $3.30 \pm 1.34$ & $3.46 \pm 0.82$ & $6.37 \pm 4.49$ & $5.44 \pm 5.79$ \\
\hline
\end{tabular}

${ }^{\mathrm{a} D o n o r s}$ of normal breast tissues were younger than breast cancer patients

be correctly interpreted for ageing processes interference with DNA methylation in patient's tumour tissue samples.

\section{DNA methylation and clinico-histopathological characteristics}

In the group of $59 \mathrm{BC}$ patients, the relationships between the DNA methylation levels of all six evaluated genes and the clinico-histopathological features such as tumour histology, tumour size, LNM status, TNM, grade (G), hormonal receptor (HR) and HER2 status, Ki-67 proliferative index, tumour multifocality and CTC presence were analysed in PT, LNM and PBC samples. We identified significant differences in methylation levels between patients with G1 and G2 BC compared to those with G3 BC. Compared to patients with G3 BC, patients with lower grades presented higher methylation levels in three genes: CXCL12 in PBCs, SNAI1 in LNMs and SNAI2 in PT samples. The mean methylation levels in G1 and G2 compared to G3 for those three genes were 3.06\% vs. $2.35 \%, 5.39 \%$ vs. $3.42 \%$, and $7.38 \%$ vs. $4.00 \%$ with $P$ values of 0.021, 0.007, and 0.003, respectively (Fig. 1). Methylation results for all six genes in patients with different histological grade are summarized in Additional file 1.

The relationship between grade and SNAI2 methylation in tumour tissue was confirmed by multivariate logistic regression analysis. The influence of the methylation of EMT-associated genes (TWIST1, SNAI1 and SNAI2) and the clinico-histopathological features of invasive $B C$, namely, age, $H R$ and HER2 status, tumour histology and $\mathrm{Ki}-67$ proliferative index on tumour grade were assessed in a multivariate model. The methylation of the SNAI2 gene negatively associated with higher tumour grade (grade 3$)(\mathrm{OR}=0.61 ; 95 \% \mathrm{CI}, 0.39-0.97$; $P=0.038)$ and higher grade positively associated with the high $\mathrm{Ki}-67$ proliferative index $(\mathrm{OR}=17.34 ; 95 \% \mathrm{CI}$, 2.89-103.88; $P=0.002$ ) (Table 4).

\section{DNA methylation and dissemination of tumour cells}

In the present study, we investigated the differences in methylation profiles between patients with haematogenous dissemination of cancer cells, indicated by the presence of
CTCs in peripheral blood, and/or lymphogenous spread, represented by the presence of LNMs.

To evaluate the association between DNA methylation and haematogenous spread, we analysed DNA methylation levels in patients with epithelial CTCs (epi CTC+) and in those undergoing EMT process, as indicated by the presence of mesenchymal CTCs (mes CTC+) in their blood. We observed significantly lower methylation levels for ADAM23, TWIST1 and SNAI2 in the PTs of patients with epi CTC+ than in the PTs of patients with epi CTC- $(4.45 \%$ vs. $11.46 \%, P=0.003 ; 13.09 \%$ vs. $24.36 \%, P=0.045$ and $4.31 \%$ vs. $7.02 \%, P=0.026$, respectively) (Fig. 2). In BC patients with mes CTC+ in circulation, significant lower methylation levels of the $A D A M 23$ gene were identified in PT and LNM tissues than in the tissues of patients with mes CTC- $(4.79 \%$ vs. $11.89 \%, P=0.023$ for PTs and $4.29 \%$ vs. $11.31 \%, P=$ 0.024 for LNMs) (Fig. 3). Additionally, we analysed methylation profiles in three groups of patients with epi $\mathrm{CTC}+$, mes CTC+ and without any CTC (CTC-) and we found the significant differences in methylation levels in SNAI1 gene between epi CTC+ and mes CTC+ patients, in SNAI2 gene between epi CTC+ and CTC- patients. For $A D A M 23$ gene the similar values were observed between patients with epi CTC+ and mes CTC+, where DNA methylation was significantly lower for both these groups when compared to CTC- patients (Table 5).

We also evaluated DNA methylation in three groups of patients with different statuses of cancer cell dissemination, namely, CTC-negative patients with LNM (CTC-LNM+, $n=29$ ), CTC-positive patients without LNM (CTC + LNM-, $n=16)$ and those positive for both parameters $(\mathrm{CTC}+\mathrm{LNM}+, n=13)$. For those analyses, one $\mathrm{BC}$ patient with micrometastasis in lymph node (LN) was excluded. We found significant differences in methylation levels among these three groups for ADAM23 in PT and LNM tissues (Fig. 4) and TWIST1 in PBCs.

The analysis of methylation levels in PTs and PBC samples between patients with exclusively haematogenous dissemination (CTC + LNM-) and those with only 


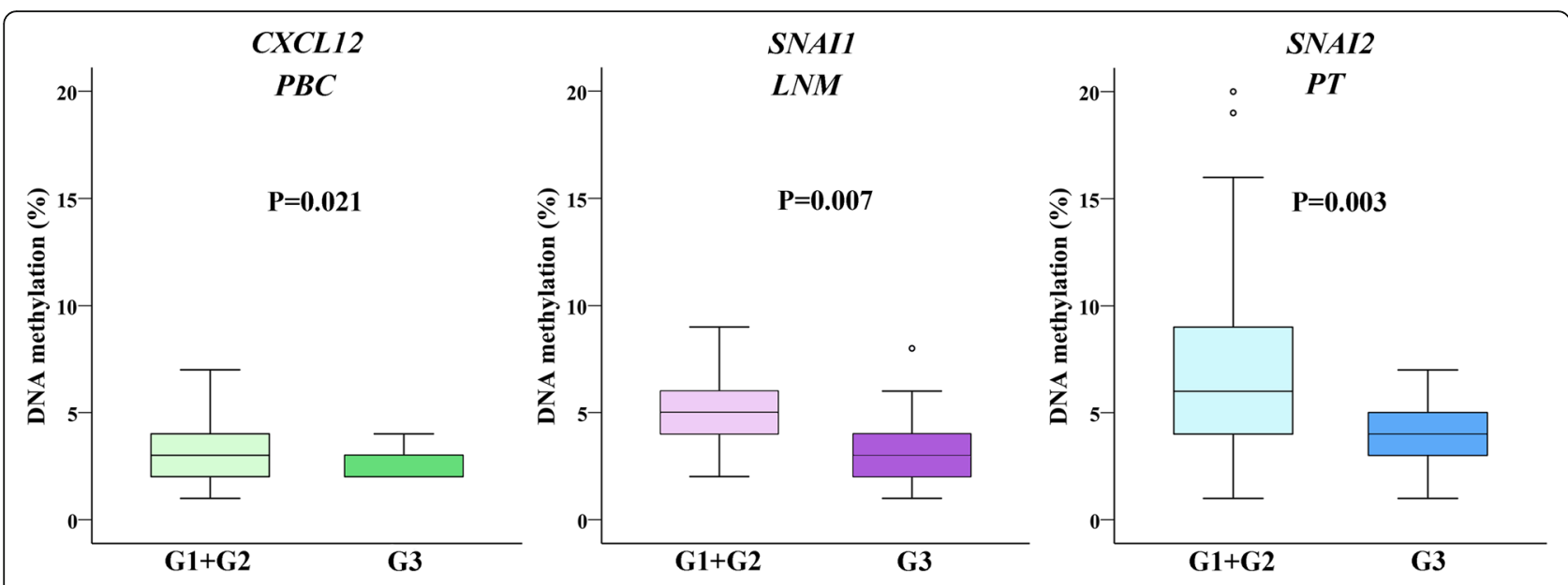

Fig. 1 DNA methylation levels in patients with different histologic grade in three types of samples for CXCL12, SNAl1 and SNAI2 genes. The length of the boxes is the interquartile range (IQR) that represents values between the 75th and 25th percentiles. The circle (o) labelled outliers (values more than 1.5 IQRs but less than 3 IQRs from the end of the box). Values more than three IQRs, extremes, are depicted by asterisk (*).The horizontal line represents median. Significance level is regarded as $P<0.05$. Abbreviations: PBC, peripheral blood cells; PT, primary tumour; LNM, lymph node metastases; G, histologic grade

lymphogenous spread (CTC-LNM+) identified significant differences between methylation levels of the ADAM23 gene in PTs and the CXCL12 and TWIST1 genes in $\mathrm{PBC}$ samples $(4.69 \%$ vs. $13.39 \%, P=0.002$; $2.31 \%$ vs. $3.03 \%, P=0.036 ; 3.31 \%$ vs. $4.48 \%, P=0.008$ ). Using multivariate logistic regression, we confirmed the inverse association between the ADAM23 methylation level in PTs and the presence of CTCs in the peripheral blood of patients $(\mathrm{OR}=0.45 ; 95 \% \mathrm{CI}, 0.23-0.90 ; P=$ 0.023) (Table 6).

\section{Discussion}

The high mortality rate associated with metastatic disease is a serious medical problem. To improve screening strategies and preventative treatment of metastatic progression in $\mathrm{BC}$ patients, detailed knowledge is needed about the molecular mechanisms that result in aggressive tumour phenotypes, including invasiveness and metastasis. In addition to many other molecular markers, DNA methylation biomarkers, particularly the specific alterations in methylation, offer tools for early detection, diagnosis and more effective management of advanced $\mathrm{BC}$.

Table 4 The risk estimation of analysed variables and clinical status for histological grade 3 in breast cancer patients (logistic regression adjusted for age)

\begin{tabular}{lllll}
\hline & Variables & $P$ value & OR & $95 \% \mathrm{Cl}$ \\
\hline Grade 3 & $\uparrow$ Methylation of SNA12 in PT & 0.038 & 0.61 & $0.39-0.97$ \\
& Ki-67 proliferation index $>20 \%$ & 0.002 & 17.34 & $2.89-103.88$ \\
\hline
\end{tabular}

-2 Log likelihood $=31.62 ; R^{2}($ Cox and Snell $)=0.43 ; R^{2}$ (Nagelkerke) $=0.60$ Abbreviations: $P T$ primary tumour, $\mathrm{OR}$ odds ratio, $\mathrm{Cl}$ confidence interval, $\uparrow$ continuous variable. Age and DNA methylation of EMT related genes, hormone receptor and HER2 status, histological type and Ki-67 proliferative index were analysed as independent variables, significant results are shown in the table
In the present study, we investigated promoter methylation in six genes associated with tumour invasivity (ADAM23, uPA, CXCL12, TWIST1, SNAI1 and SNAI2). We found significantly different methylation levels for CXCL12, TWIST1 and SNAI2 genes in tumours of BC patients compared with healthy breast tissues, with mean values of $13.4 \%, 21.9 \%$ and $6.37 \%$, respectively; however, these relations could be influenced by the fact that $\mathrm{BC}$ patients were older than healthy donors. With the process of aging, especially after the menopause, mammary glands undergo involution. Both glandular parenchyma and connective tissue atrophy with reduction of adipose tissue. These morphological changes are accompanied with molecular alterations including DNA methylation. In normal breast tissues, the age-related methylation in 204 CpG loci was observed, which progressively alterated in breast tumours [58]. Therefore, for evaluation of cancer-specific methylation profiles, the younger persons cannot be accepted as accurate controls to $\mathrm{BC}$ patients, who undergone the aging processes.

In 206 patients, the methylation level of the CXCL12 gene was $12.04 \%$ [17]; however, in another laboratory, quantitative methylation analyses of CXCL12 gene were performed in only three $\mathrm{BC}$ samples, with variable methylation levels detected, ranging from 6 to 89\% [30]. Other authors observed slightly lower mean levels of TWIST1 methylation than we evidenced in our study, namely, $17.5 \%$ and $15.3 \%[35,36]$, but Gort and colleagues determined a higher methylation level of TWIST1 in 76 samples of invasive BC, with a mean of 34\% [37]. The median of our results for TWIST1 methylation (18.5\%) is approximately two-fold higher than the median of $8.85 \%$ measured in $\mathrm{BC}$ patients by other 


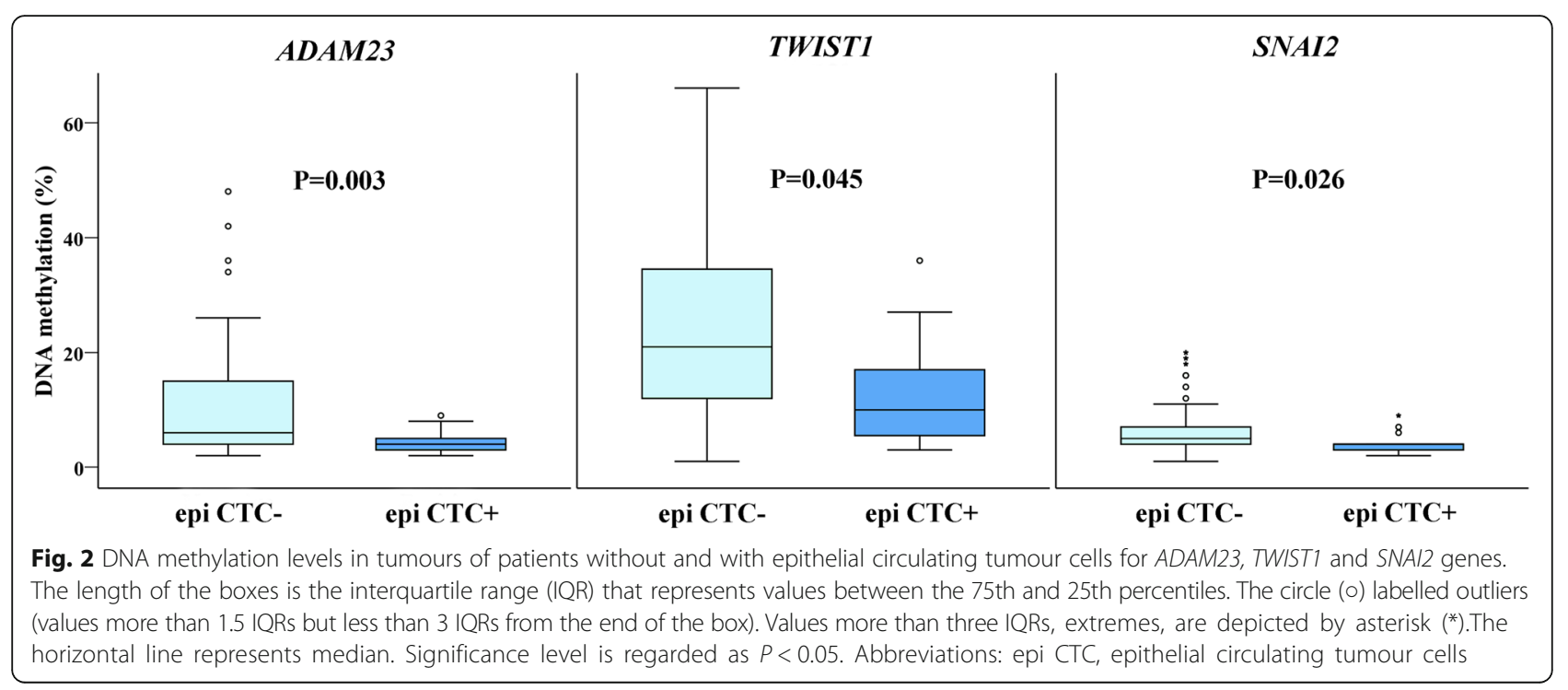

researchers using the same pyrosequencing method [59]. In $\mathrm{BC}$ cell lines, an inverse association between DNA methylation and the transcription levels of the SNAI1 and SNAI2 genes has been documented [40]. These in vitro results together with ours in $\mathrm{BC}$ patients indicate that in addition to CXCL12 and TWIST1 methylation, the aberrant methylation profile of the SNAI2 gene could also contribute to the invasivity of $\mathrm{BC}$.

For the appropriate staging of $\mathrm{BC}$, the tumour size and lymph node status are considered to be the most important clinical categories. However, the histologic grade, which characterizes the degree of cancer cell differentiation, has not yet been integrated into the TNM classification. In a recent meta-analysis, the prognostic importance of histologic grade for overall survival was documented, without any association with tumour size or nodal status [60]. Moreover, integrative bioinformatics analyses have identified the 22-gene tumour aggressiveness grading classifier that indicate the variable features of cancer cells in tumour tissues with different levels of de-differentiation because of individual sets of aberrant genetic changes [61]. To the best of our knowledge, no study has been published that investigated the association between changes in whole-genome methylation profiles and cancer de-differentiation processes.

It is generally accepted that the SLUG (SNAI2) transcription factor, encoded by the SNAI2 gene, induces EMT, initiating cancer dissemination processes. This fact was supported by a previous study, in which the higher expression levels of the SLUG protein and SLUG mRNA were observed in the tumours of patients with metastatic $\mathrm{BC}$ or disease recurrence [34]. Moreover, the results of an in vitro study documented epigenetic regulation through promoter methylation in both the SNAI1 and SNAI2 genes during EMT and reverse mesenchymalepithelial transition [40]. However, our results indicate the

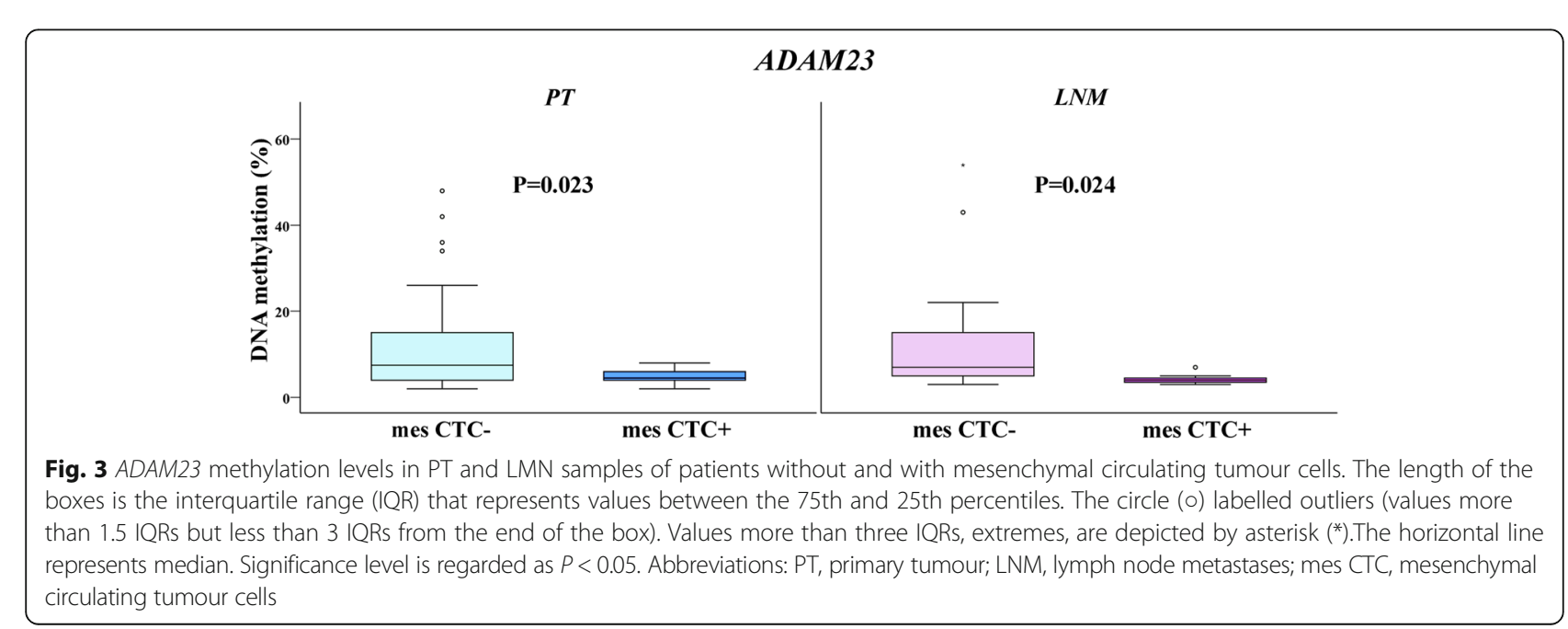


Table 5 DNA methylation levels in primary tumours of CTCnegative and epithelial CTC and mesenchymal CTC-positive $B C$ patients

\begin{tabular}{lllll}
\hline & \multicolumn{3}{l}{ DNA methylation levels in primary tumour } & \\
\cline { 2 - 4 } Genes & CTC- & epi CTC + & mes CTC+ & \\
\hline ADAM23 & $14.17 \pm 12.24^{\mathrm{a}, \mathrm{b}}$ & $4.56 \pm 2.40^{\mathrm{a}}$ & $4.92 \pm 1.62^{\mathrm{b}}$ & $\mathbf{0 . 0 0 1}$ \\
UPA & $13.29 \pm 16.37$ & $9.56 \pm 8.75$ & $19.33 \pm 21.90$ & 0.592 \\
CXCL12 & $14.45 \pm 14.09$ & $7.10 \pm 3.00$ & $16.40 \pm 15.51$ & 0.287 \\
TWIST1 & $24.08 \pm 18.20$ & $10.00 \pm 8.55$ & $24.86 \pm 16.34$ & 0.065 \\
SNAI1 & $5.82 \pm 7.14$ & $2.89 \pm 1.05^{\mathrm{c}}$ & $8.40 \pm 7.80^{\mathrm{C}}$ & $\mathbf{0 . 0 0 4}$ \\
SNAI2 & $7.11 \pm 4.95^{\mathrm{d}}$ & $3.70 \pm 1.34^{\mathrm{d}}$ & $6.85 \pm 4.90$ & $\mathbf{0 . 0 2 2}$ \\
\hline
\end{tabular}

${ }^{*}$ Kruskal-Wallis Test; Adjusted pairwise comparisons: ${ }^{\mathrm{a}} P=0.003 ;{ }^{\mathrm{b}} P=0.015 ;{ }^{\mathrm{c}} P=$ $0.004 ;{ }^{d} P=0.018 ;$ A statistical two-tailed significance was regarded as $P$ value $<0.05$. Abbreviations: $B C$ breast cancer, CTC circulating tumour cell, epi CTC epithelial circulating tumour cells, mes CTC mesenchymal circulating tumour cells

other possible role of the SNAI2 gene in $\mathrm{BC}$, which is the de-differentiation of cancer cells. SNAI2 involvement in cell differentiation has been shown in human epidermal progenitor cells. Overexpressed SNAI2 inhibits the differentiation of these cells by binding to the differentiation and adhesion genes across the genome. On the other hand, low levels of SNAI2, and therefore weak binding during epidermal differentiation, lead to the full expression of the differentiation programme. Similar processes could be expected in cancer cells in which high levels of SNAI2 result in more intensive binding of SNAI2 to the genomic targets, determining the differentiation status of epithelial cells. Cancer cells then trigger EMT and the inhibition of cell differentiation [62]. Based on the assumption that decreased methylation could allow the up-regulation of SNAI2 gene expression, reduced differentiation in tumours could be expected, as was observed in our study by the inverse relationship between SNAI2 methylation and histologic grade.

Two important roles in cancer cell spread are played by ADAM proteins performing proteinase activities through the metalloproteinase domain and regulating cell adhesion by their interaction with integrins, which participate in tumour growth and metastasis as well as in tumour angiogenesis [63]. Among the ADAM proteins, proteolytically inactive ADAM23 negatively regulates cancer cell migration by binding $\alpha v \beta 3$ integrin to its disintegrin domain [15]. In addition to cell migration, the active integrins promote the interaction between CTCs and thrombocytes, thereby mediating the protection of cancer cells against degradation in the vasculature [64]. In BC cell lines, Costa and colleagues found that $A D A M 23$ promoter hypermethylation was strongly associated with the reduction in mRNA and protein expression, and they also observed higher methylation levels in PTs with more advanced grade [16]. In our study, we investigated whether there are differences in methylation levels in $\mathrm{BC}$ patients with different routes of cancer dissemination. We found significantly lower ADAM23 methylation levels in tumours of CTC-positive patients, regardless of their epithelial or mesenchymal phenotype, than in tumours of patients with LNM. Our results indicate that the higher expression level of the $A D A M 23$ gene could contribute to its newly identified function in the haematogenous dissemination of $\mathrm{BC}$.

The dissemination of cancer cells is performed via blood and lymphatic vessels after neo-vascularization and neo-lymphangiogenesis in tumour tissue [65]. In a very interesting study, the molecular features of endothelial cells (EC) located in tumour-associated vasculature were studied to evaluate a new strategy to inhibit tumour growth and cancer dissemination. In this model of EC purified and cultured from ovarian cancer and normal adrenal glands as control tissues, the authors identified 158 highly expressed transcripts. Of these mRNAs, the ADAM23, FAP, GPMNB and PRSS3 were found in the tumour-derived endothelium, but no expression was observed in tumour cells. Moreover, $A D A M 23, G P M N B$ and PRSS3 expression only occurred in the blood vessels of human cancer samples [66]. These

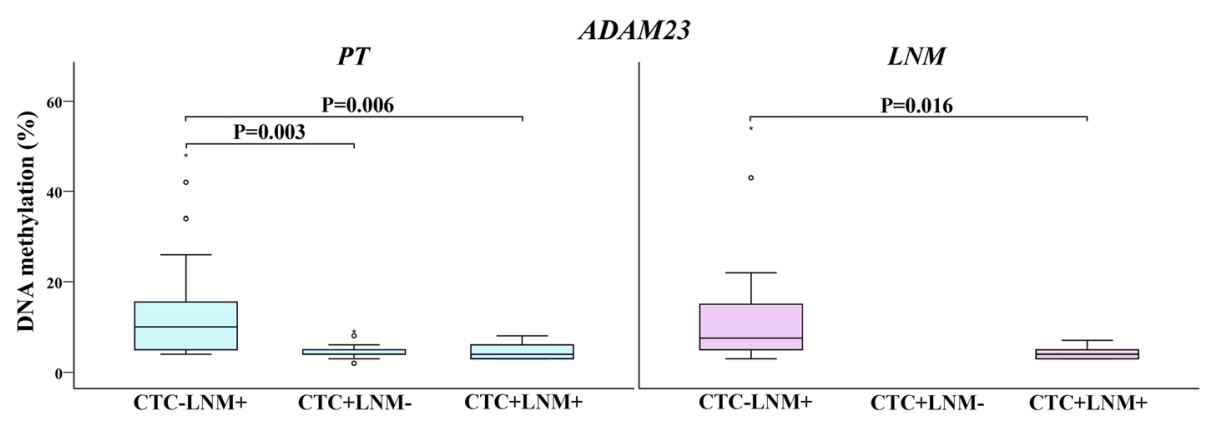

Fig. 4 ADAM23 methylation levels in PT and LMN samples of patients with different statuses of cancer cell dissemination characterized by CTC and/or LMN presence. The length of the boxes is the interquartile range (IQR) that represents values between the 75 th and 25 th percentiles. The circle (o) labelled outliers (values more than 1.5 IQRs but less than 3 IQRs from the end of the box). Values more than three IQRs, extremes, are depicted by asterisk $(*)$.The horizontal line represents median. Significance level is regarded as $P<0.05$. Abbreviations: PT, primary tumour; LNM, lymph node metastases; CTC, circulating tumour cells 
Table 6 The risk estimation of analysed variables and clinical status for exclusively haematogenous versus lymphogenous dissemination in breast cancer patients (logistic regression adjusted for age)

\begin{tabular}{lllll}
\hline & Variables & $P$ value & OR & $95 \% \mathrm{Cl}$ \\
\hline CTC+LNM- vs. & $\uparrow$ Methylation of & 0.023 & 0.45 & $0.229-0.898$ \\
CTC-LNM+ & ADAM23 in PT & & & \\
& $\uparrow$ Methylation of & 0.046 & 0.07 & $0.005-0.949$ \\
& CXCL12 in PBCs & & & \\
& $\uparrow$ Methylation of & 0.050 & 0.03 & $0.001-0.998$ \\
& TWIST1 in PBCs & & & \\
& Tumour size $>20 \mathrm{~mm}$ & 0.055 & 0.04 & $0.001-1.073$
\end{tabular}

-2 Log likelihood $=15.22 ; R^{2}$ (Cox and Snell) $=0.57 ; R^{2}$ (Nagelkerke) $=0.81$ Abbreviations: LNM lymph node metastases, CTC circulating tumour cells, OR odds ratio, $\mathrm{Cl}$ confidence interval, $\uparrow$ continuous variable. Age and DNA methylation of genes significant in univariate analysis, hormone receptor and HER2 status, histological type, tumour size and Ki-67 proliferative index were analysed as independent variables, significant or borderline significant results are shown in the table

findings seem to not be organ-specific but rather to be exclusive to tumour-derived EC because expression of several genes that are typical for tumour vasculature was also observed in other types of malignancies in the colon, brain and breast [67-69]. In the context of our results, we consider that decreased methylation of the ADAM23 gene could partially represent the molecular profile of EC from the tissue surrounding the tumour body rather than from the tumour cells. Therefore, patients with higher ADAM23 expression levels, which may be the result of decreased promoter methylation, could have contributed to the dense development of tumour blood vessels, resulting in the haematogenous rather than the lymphogenous spread of cancer cells.

\section{Conclusions}

In our study, among the selected genes related to the partial processes of cancer cell invasivity, we identified higher cancer-specific methylation levels in the CXCL12, TWIST1 and SNAI2 genes. In contrast to CXCL12 and TWIST1 methylation, the epigenetic regulation of the SNAI2 gene was previously determined only in $\mathrm{BC}$ cell line models, not in tumour samples. Furthermore, the decreased methylation of the SNAI2 gene in tumours with histologic grade 3 indicates a new function of a typical EMT gene in cancer cell de-differentiation. The differences in ADAM23 methylation profiles in BC patients with various route of cancer cells dissemination suggest that ADAM23 could participate in haematogenous spread. Our research uncovers new relationships between aberrant methylation profiles and clinical characteristics of advanced BC. However, experimental investigation of the associated molecular mechanisms is needed before the SNAI2 and ADAM23 methylation profiles can contribute to the management of metastatic progression in $\mathrm{BC}$.

\section{Additional file}

Additional file 1: DNA methylation levels in various types of samples from BC patients with different histological grade. A table containing methylation results for all six genes and statistical evaluation between two groups of patients with $\mathrm{G} 1+\mathrm{G} 2$ and $\mathrm{G} 3$ tumours in samples of peripheral blood cells, primary tumours and lymph node metastases. (DOCX $15 \mathrm{~kb}$ )

\section{Abbreviations}

ADAM: A disintegrin and metalloproteases; ANOVA: Analysis of variance; BC: Breast cancer; BM: Basement membrane; CD45+: CD45-positive; CTCs: Circulating tumour cells; EC: Endothelial cell; ECM: Extracellular matrix; EMT: Epithelial-mesenchymal transition; epi CTC: Epithelial circulating tumour cell; FFPE: Formalin fixed paraffin-embedded tissue; G: Grade; HGF: Hepatocyte growth factor; HR: Hormonal receptor; LN: Lymph node; LNMs: Lymph node metastases; mes CTC: Mesenchymal circulating tumour cell; PBCs: Peripheral blood cells; PT: Primary tumour; qRTPCR: Quantitative real-time polymerase chain reaction; TFs: Transcription factors; TN: Triple-negative; VEGF: Vascular endothelial growth factor

\section{Acknowledgements}

The authors would like to thank the surgeons Marian Karaba, Juraj Benca and Martin Bohac for providing the collection of breast tumour and normal breast tissue samples.

\section{Funding}

This publication is the result of the implementation of several research projects funded by the Scientific Grant Agency of the Ministry of Education, science, research and sport of the Slovak Republic and Slovak Academy of Sciences (grants VEGA 2/0092/15 and VEGA 2/0102/17), the European Fund for Regional Development through Operation Program of Research and Development (project code ITMS 26240220058), and the Slovak Research and Development Agency (grants APW-0076-10, APW-14-0327 and APW-16-0010). These agencies had no role in the design of the study and collection, analysis, and interpretation of data and in writing and in the decision to submit the manuscript for publication.

\section{Availability of data and materials}

All data generated or analysed during this study are included in this published article.

\section{Authors' contributions}

IF is the author of conception and design of this study. MM participated in selection of patients, collection of samples, informed consent obtaining, clinico-pathological data collection. ZC performed histological examination and separation of representative samples of tumour and normal breast tissues. LK, IZ, BS and VHK performed preparation of blood and tissue samples and analyses of DNA methylation. GM and TS were involved in CTCs detection and analysis and BS and LK performed statistical analysis. IF and LK participated in manuscript preparation. All authors read and approved the final manuscript.

\section{Ethics approval and consent to participate}

This study was approved by the Institutional Review Board of the National Cancer Institute of Slovakia. All procedures performed in studies involving human participants were in accordance with the ethical standards of the institutional and/or national research committee and with the 1964 Helsinki declaration and its later amendments or comparable ethical standards. Informed consent was obtained from all individual participants included in the study.

\section{Consent for publication}

Not applicable.

\section{Competing interests}

The authors declare that they have no competing interests. 


\section{Publisher's Note}

Springer Nature remains neutral with regard to jurisdictional claims in published maps and institutional affiliations.

\begin{abstract}
Author details
'Department of Genetics, Cancer Research Institute, Biomedical Research Center, Slovak Academy of Sciences, v.vi.., Dubravska cesta 9, 84505 Bratislava, Slovak Republic. ${ }^{2}$ Institute of Molecular Biomedicine, Faculty of Medicine, Comenius University, Sasinkova 4, 81108 Bratislava, Slovak Republic. ${ }^{3}$ Institute of Pathological Anatomy, Faculty of Medicine, Comenius University, University Hospital, Sasinkova 4, 81108 Bratislava, Slovak Republic. ${ }^{4}$ 2nd Department of Oncology, Faculty of Medicine, Comenius University, National Cancer Institute, Klenova 1, 83310 Bratislava, Slovak Republic.
\end{abstract}

\section{Received: 14 March 2018 Accepted: 29 August 2018} Published online: 06 September 2018

\section{References}

1. Torre LA, Bray F, Siegel RL, Ferlay J, Lortet-Tieulent J, Jemal A. Global cancer statistics. 2012. CA Cancer J Clin. 2015;65:87-108.

2. Tevaarwerk AJ, Gray RJ, Schneider BP, Smith ML, Wagner LI, Fetting JH, et al. Survival in patients with metastatic recurrent breast cancer after adjuvant chemotherapy: little evidence of improvement over the past 30 years. Cancer. 2013;119:1140-8.

3. Jones PA, Baylin SB. The epigenomics of cancer. Cell. 2007;128:683-92.

4. Esteller M. Cancer epigenomics: DNA methylomes and histone-modification maps. Nat Rev Genet. 2007;8:286-98.

5. Lin IH, Chen DT, Chang YF, Lee YL, Su CH, Cheng C, et al. Hierarchical clustering of breast cancer methylomes revealed differentially methylated and expressed breast cancer genes. PLoS One. 2015:10:e0118453.

6. Gupta GP, Massagué J. Cancer metastasis: building a framework. Cell. 2006; 127:679-95.

7. Seyfried TN, Huysentruyt LC. On the origin of cancer metastasis. Crit Rev Oncog. 2013;18:43-73.

8. Páez D, Labonte MJ, Bohanes P, Zhang W, Benhanim L, Ning Y, et al. Cance dormancy: a model of early dissemination and late cancer recurrence. Clin Cancer Res. 2012;18:645-53.

9. Chaffer CL, Weinberg RA. A perspective on cancer cell metastasis. Science. 2011:331:1559-64.

10. Tanner K. Regulation of the basement membrane by epithelia generated forces. Phys Biol. 2012:9:065003.

11. Duffy MJ, Mullooly M, O'Donovan N, Sukor S, Crown J, Pierce A, et al. The ADAMs family of proteases: new biomarkers and therapeutic targets for cancer? Clin Proteomics. 2011:8:9.

12. Giebeler N, Zigrino P. A Disintegrin and Metalloprotease (ADAM): Historical Overview of Their Functions. Toxins (Basel). 2016;8:122.

13. Cal S, Freije JM, López JM, Takada Y, López-Otín C. ADAM 23/MDC3, a human disintegrin that promotes cell adhesion via interaction with the alphavbeta3 integrin through an RGD-independent mechanism. Mol Biol Cell. 2000;11:1457-69.

14. Wang L, Hoggard JA, Korleski ED, Long GV, Ree BC, Hensley K, et al. Multiple non-catalytic ADAMs are novel integrin a4 ligands. Mol Cell Biochem. 2018; 442:29-38

15. Verbisck NV, Costa ET, Costa FF, Cavalher FP, Costa MD, Muras A, et al. ADAM23 negatively modulates alpha(v)beta(3) integrin activation during metastasis. Cancer Res. 2009:69:5546-52.

16. Costa FF, Verbisck NV, Salim AC, lerardi DF, Pires LC, Sasahara RM, et al. Epigenetic silencing of the adhesion molecule ADAM23 is highly frequent in breast tumors. Oncogene. 2004;23:1481-8.

17. Fridrichova I, Smolkova B, Kajabova V, Zmetakova I, Krivulcik T, Mego M, et al. CXCL12 and ADAM23 hypermethylation are associated with advanced breast cancers. Transl Res. 2015;165:717-30.

18. Santibanez JF, Krstic J. Transforming Growth Factor-Beta and Urokinase Type Plasminogen Interplay in Cancer. Curr Protein Pept Sci. 2017; doi.org/10. 2174/1389203718666171030103801

19. Frandsen TL, Holst-Hansen C, Nielsen BS, Christensen IJ, Nyengaard JR, Carmeliet $\mathrm{P}$, et al. Direct evidence of the importance of stromal urokinase plasminogen activator (UPA) in the growth of an experimental human breast cancer using a combined uPA gene-disrupted and immunodeficient xenograft model. Cancer Res. 2001;61:532-7.
20. Bekes EM, Deryugina El, Kupriyanova TA, Zajac E, Botkjaer KA, Andreasen PA, et al. Activation of pro-uPA is critical for initial escape from the primary tumor and hematogenous dissemination of human carcinoma cells. Neoplasia. 2011:13:806-21.

21. Witzel I, Milde-Langosch K, Schmidt M, Karn T, Becker S, Wirtz R, et al. Role of urokinase plasminogen activator and plasminogen activator inhibitor mRNA expression as prognostic factors in molecular subtypes of breast cancer. Onco Targets Ther. 2014;7:2205-13.

22. Guo Y, Pakneshan P, Gladu J, Slack A, Szyf M, Rabbani SA. Regulation of DNA methylation in human breast cancer. Effect on the urokinase-type plasminogen activator gene production and tumor invasion. J Biol Chem. 2002;277:41571-9

23. Pakneshan P, Szyf M, Farias-Eisner R, Rabbani SA. Reversal of the hypomethylation status of urokinase (UPA) promoter blocks breast cancer growth and metastasis. J Biol Chem. 2004a;279:31735-44.

24. Pakneshan P, Têtu B, Rabbani SA. Demethylation of urokinase promoter as a prognostic marker in patients with breast carcinoma. Clin Cancer Res. 2004b; 10:3035-41.

25. Chen $\mathrm{CM}$, Chen HL, Hsiau TH, Hsiau AH, Shi H, Brock GJ, et al. Methylation target array for rapid analysis of $\mathrm{CpG}$ island hypermethylation in multiple tissue genomes. Am J Pathol. 2003;163:37-45.

26. Chang C, Werb Z. The many faces of metalloproteases: cell growth, invasion, angiogenesis and metastasis. Trends Cell Biol. 2001;11:S37-43.

27. Sun Y, Mao X, Fan C, Liu C, Guo A, Guan S, et al. CXCL12-CXCR4 axis promotes the natural selection of breast cancer cell metastasis. Tumour Biol. 2014;35:7765-73.

28. Ray P, Stacer AC, Fenner J, Cavnar SP, Meguiar K, Brown M, et al. CXCL12- $y$ in primary tumors drives breast cancer metastasis. Oncogene. 2015;34:2043-51.

29. Zhou W, Jiang Z, Liu N, Xu F, Wen P, Liu Y, et al. Down-regulation of CXCL12 mRNA expression by promoter hypermethylation and its association with metastatic progression in human breast carcinomas. J Cancer Res Clin Oncol. 2009:135:91-102.

30. Ramos EA, Camargo AA, Braun K, Slowik R, Cavalli IJ, Ribeiro EM, et al. Simultaneous CXCL12 and ESR1 CpG island hypermethylation correlates with poor prognosis in sporadic breast cancer. BMC Cancer. 2010;10:23.

31. Ramos EA, Grochoski M, Braun-Prado K, Seniski GG, Cavalli IJ, Ribeiro EM, et al. Epigenetic changes of CXCR4 and its ligand CXCL12 as prognostic factors for sporadic breast cancer. PLoS One. 2011;6:e29461.

32. Kalluri $R$, Weinberg RA. The basics of epithelial-mesenchymal transition. J Clin Invest. 2009;119:1420-8.

33. Sánchez-Tilló E, Liu Y, de Barrios O, Siles L, Fanlo L, Cuatrecasas M, et al. EMT-activating transcription factors in cancer: beyond EMT and tumor invasiveness. Cell Mol Life Sci. 2012;69:3429-56.

34. Martin TA, Goyal A, Watkins $G$, Jiang WG. Expression of the transcription factors snail, slug, and twist and their clinical significance in human breast cancer. Ann Surg Oncol. 2005;12:488-96.

35. Cho YH, Yazici H, Wu HC, Terry MB, Gonzalez K, Qu M, et al. Aberrant promoter hypermethylation and genomic hypomethylation in tumor, adjacent normal tissues and blood from breast cancer patients. Anticancer Res. 2010;30:2489-96.

36. Cho YH, Shen J, Gammon MD, Zhang YJ, Wang Q, Gonzalez K, et al. Prognostic significance of gene-specific promoter hypermethylation in breast cancer patients. Breast Cancer Res Treat. 2012:131:197-205.

37. Gort EH, Suijkerbuijk KP, Roothaan SM, Raman V, Vooijs M, van der Wall E, et al. Methylation of the TWIST1 promoter, TWIST1 mRNA levels, and immunohistochemical expression of TWIST1 in breast cancer. Cancer Epidemiol Biomark Prev. 2008;17:3325-30.

38. Branham MT, Marzese DM, Laurito SR, Gago FE, Orozco II, Tello OM, et al. Methylation profile of triple-negative breast carcinomas. Oncogenesis. 2012;1:e17.

39. Fackler MJ, McVeigh M, Evron E, Garrett E, Mehrotra J, Polyak K, et al. DNA methylation of RASSF1A, HIN-1, RAR-beta, cyclin D2 and twist in in situ and invasive lobular breast carcinoma. Int J Cancer. 2003:107:970-5.

40. Chen Y, Wang K, Qian CN, Leach R. DNA methylation is associated with transcription of snail and slug genes. Biochem Biophys Res Commun. 2013; 430:1083-90.

41. Rodenhiser DI, Andrews J, Kennette W, Sadikovic B, Mendlowitz A, Tuck AB, et al. Epigenetic mapping and functional analysis in a breast cancer metastasis model using whole-genome promoter tiling microarrays. Breast Cancer Res. 2008;10:R62

42. Paduch R. The role of lymphangiogenesis and angiogenesis in tumor metastasis. Cell Oncol (Dordr). 2016;39:397-410. 
43. Stacker SA, Baldwin ME, Achen MG. The role of tumor lymphangiogenesis in metastatic spread. FASEB J. 2002;16:922-34.

44. Lee E, Pandey NB, Popel AS. Crosstalk between cancer cells and blood endothelial and lymphatic endothelial cells in tumour and organ microenvironment. Expert Rev Mol Med. 2015;17:e3.

45. Sigurdsson $\mathrm{V}$, Hilmarsdottir $\mathrm{B}$, Sigmundsdottir $\mathrm{H}$, Fridriksdottir AJ, Ringnér $\mathrm{M}$, Villadsen $\mathrm{R}$, et al. Endothelial induced EMT in breast epithelial cells with stem cell properties. PLoS One. 2011;6:e23833.

46. Scher HI, Heller G, Molina A, Attard G, Danila DC, Jia X, et al. Circulating tumor cell biomarker panel as an individual-level surrogate for survival in metastatic castration-resistant prostate cancer. J Clin Oncol. 2015;33:1348-55.

47. Romiti A, Raffa S, Di Rocco R, Roberto M, Milano A, Zullo A, et al. Circulating tumor cells count predicts survival in colorectal cancer patients. J Gastrointestin Liver Dis. 2014;23:279-84.

48. Hou JM, Krebs MG, Lancashire L, Sloane R, Backen A, Swain RK, et al. Clinical significance and molecular characteristics of circulating tumor cells and circulating tumor microemboli in patients with small-cell lung cancer. J Clin Oncol. 2012;30:525-32.

49. Zhang L, Riethdorf S, Wu G, Wang T, Yang K, Peng G, et al. Meta-analysis of the prognostic value of circulating tumor cells in breast cancer. Clin Cancer Res. 2012;18:5701-10.

50. Skobe $M$, Hawighorst $T$, Jackson DG, Prevo R, Janes L, Velasco P, et al. Induction of tumor lymphangiogenesis by VEGF-C promotes breast cancer metastasis. Nat Med. 2001;7:192-8.

51. Wong SY, Hynes RO. Lymphatic or hematogenous dissemination: how does a metastatic tumor cell decide? Cell Cycle. 2006;5:812-7.

52. Nathanson SD, Kwon D, Kapke A, Alford SH, Chitale D. The role of lymph node metastasis in the systemic dissemination of breast cancer. Ann Surg Oncol. 2009;16:3396-405.

53. Wolff AC, Hammond ME, Hicks DG, Dowsett M, MCShane LM, Allison KH, et al. Recommendations for human epidermal growth factor receptor 2 testing in breast cancer: American Society of Clinical Oncology/College of American Pathologists clinical practice guideline update. Arch Pathol Lab Med. 2014;138:241-56.

54. Zmetakova I, Danihel L, Smolkova B, Mego M, Kajabova V, Krivulcik T, et al. Evaluation of protein expression and DNA methylation profiles detected by pyrosequencing in invasive breast cancer. Neoplasma. 2013;60:635-46.

55. Cierna Z, Mego M, Janega P, Karaba M, Minarik G, Benca J, et al. Matrix metalloproteinase 1 and circulating tumor cells in early breast cancer. BMC Cancer. 2014:14:472.

56. Mego M, Karaba M, Minarik G, Benca J, Sedlackova T, Tothova L, et al. Relationship between circulating tumor cells, blood coagulation, and urokinase-plasminogen- activator system in early breast cancer patients. Breast J. 2015;21:155-60.

57. Mego M, Cholujova D, Minarik G, Sedlackova T, Gronesova P, Karaba M, et al. CXCR4-SDF-1 interaction potentially mediates trafficking of circulating tumor cells in primary breast cancer. BMC Cancer. 2016;16:127.

58. Johnson KC, Koestler DC, Cheng C, Christensen BC. Age-related DNA methylation in normal breast tissue and its relationship with invasive breast tumor methylation. Epigenetics. 2014;9:268-75.

59. Cheol Kim D, Thorat MA, Lee MR, Cho SH, Vasiljević N, Scibior-Bentkowska $D$, et al. Quantitative DNA methylation and recurrence of breast cancer: a study of 30 candidate genes. Cancer Biomark. 2012;11:75-88.

60. Schwartz AM, Henson DE, Chen D, Rajamarthandan S. Histologic grade remains a prognostic factor for breast cancer regardless of the number of positive lymph nodes and tumor size: a study of 161708 cases of breast cancer from the SEER program. Arch Pathol Lab Med. 2014;138:1048-52.

61. Aswad L, Yenamandra SP, Ow GS, Grinchuk O, Ivshina AV, Kuznetsov VA. Genome and transcriptome delineation of two major oncogenic pathways governing invasive ductal breast cancer development. Oncotarget. 2015;6: 36652-74.

62. Mistry DS, Chen Y, Wang Y, Zhang K, Sen GL. SNAI2 controls the undifferentiated state of human epidermal progenitor cells. Stem Cells. 2014;32:3209-18.

63. Reiss K, Ludwig A, Saftig P. Breaking up the tie: disintegrin-like metalloproteinases as regulators of cell migration in inflammation and invasion. Pharmacol Ther. 2006;11:985-1006.

64. Felding-Habermann B, O'Toole TE, Smith JW, Fransvea E, Ruggeri ZM, Ginsberg $\mathrm{MH}$, et al. Integrin activation controls metastasis in human breast cancer. Proc Natl Acad Sci U S A. 2001;98:1853-8.
65. Witte $M H$, Dellinger MT, McDonald DM, Nathanson SD, Boccardo FM, Campisi CC, et al. Lymphangiogenesis and hemangiogenesis: potential targets for therapy. J Surg Oncol. 2011;103:489-500.

66. Ghilardi C, Chiorino G, Dossi R, Nagy Z, Giavazzi R, Bani M. Identification of novel vascular markers through gene expression profiling of tumor-derived endothelium. BMC Genomics. 2008;9:201.

67. St Croix B, Rago C, Velculescu V, Traverso G, Romans KE, Montgomery E, et al. Genes expressed in human tumor endothelium. Science. 2000;289:1197202.

68. Madden SL, Cook BP, Nacht M, Weber WD, Callahan MR, Jiang Y, et al. Vascular gene expression in nonneoplastic and malignant brain. Am J Pathol. 2004;165:601-8.

69. Parker BS, Argani P, Cook BP, Liangfeng H, Chartrand SD, Zhang M, et al. Alterations in vascular gene expression in invasive breast carcinoma. Cancer Res. 2004:64:7857-66.

\section{Ready to submit your research? Choose BMC and benefit from:}

- fast, convenient online submission

- thorough peer review by experienced researchers in your field

- rapid publication on acceptance

- support for research data, including large and complex data types

- gold Open Access which fosters wider collaboration and increased citations

- maximum visibility for your research: over $100 \mathrm{M}$ website views per year

At BMC, research is always in progress.

Learn more biomedcentral.com/submissions 